\title{
Comparação da qualidade dos tecidos do pecíolo de buriti (Mauritia flexuosa L. f.) para combustão e carbonização
}

\author{
Comparison of the quality of buriti (Mauritia flexuosa L. f.) petiole tissues for \\ combustion and carbonization
}

\author{
Lyssa Martins de Souza', Jefferson Bezerra Bezerra ${ }^{\mathrm{II}}$, \\ Wiully Luan Valverde de Queiroz ${ }^{\mathrm{II}}$, \\ Paulo Fernando Trugilho ${ }^{\mathrm{IV}}$, Thiago de Paula Protásiov, \\ Tiago Marcolino de Souza ${ }^{\mathrm{VI}}$, Lina Bufalino ${ }^{\mathrm{VII}}$
}

\section{Resumo}

Apesar da importância social, cultural e econômica para a Região Amazônica, o potencial energético da Mauritia flexuosa, popularmente conhecida como buriti, ainda não foi explorado para ampliar as possibilidades de uso dessa espécie pelas comunidades locais. Assim, o objetivo deste trabalho é comparar o potencial dos tecidos que compõem o pecíolo de Mauritia flexuosa para combustão e carbonização. O miolo e casca do pecíolo foram separados e caracterizados por composição química (extrativos removíveis por água e totais, lignina e cinzas), umidade base úmida, composição imediata (teores de materiais voláteis, carbono fixo e cinzas), densidade básica, poder calorífico superior e análise termogravimétrica em atmosfera inerte de N2. Os dois tecidos do pecíolo de Mauritia flexuosa apresentaram vantagens para finalidades bioenergéticas, como: baixo teor de cinzas $(\leq 2 \%)$, além de teor de carbono fixo $(\approx 18 \%)$ e poder calorífico superior ( $\approx 18 \mathrm{MJ} \mathrm{kg}-1)$ adequados. Para miolo e casca, os teores de lignina (19 e $28 \%$, respectivamente), extrativos (8,9 e 5\%, respectivamente), e densidade básica ( 0,041 e $0,267 \mathrm{~g} \mathrm{~cm}-3$, respectivamente) diferiram significativamente. Contudo, a composição imediata dos tecidos não foi influenciada por essas diferenças, ao contrário do poder calorífico e densidade energética. O comportamento termogravimétrico demonstrou taxa de degradação superior e rendimento final em massa inferior (7\%) para o miolo em relação à casca. A casca apresentou melhor qualidade para combustão e carbonização em comparação ao miolo. Esse resultado é vantajoso para as comunidades extrativistas da Amazônia, pois a casca é um resíduo do processamento do pecíolo para obtenção do miolo, destinado à produção de artesanatos. Pela baixa densidade básica, o miolo é mais indicado para torrefação, densificação, pirólise para geração de bio-óleo e produção de filtros naturais e carvões ativados do que para combustão direta e carbonização.

Palavras-chave: Poder calorífico; Densidade energética; Degradação térmica

Engenheira Florestal, MSc., Programa de Pós-Graduação em Ciências Florestais, Universidade Federal Rural da Amazônia, Av. Perimetral, 2501, Terra Firme, CEP 66077-830, Belém (PA), Brasil. lysaflorestal@gmail.com (ORCID: 0000-0002-2206-2275)

II Engenheiro Ambiental, MSc., Programa de Pós-Graduação em Ciências Ambientais, Universidade Federal do Amapá, Rod. Juscelino Kubitschek, KM-02 Jardim Marco Zero, CEP 68903-419, Macapá (AP), Brasil. eng.amb.jeffe@gmail.com (ORCID: 0000-0001-9371-7569)

III Engenheiro Florestal, MSc., Servidor Público Estadual da Secretaria de Estado de Meio Ambiente e Sustentabilidade, Tv. Lomas Valentinas, 2717, Marco, CEP 66093-677, Belém (PA), Brasil. wiullylvqueiroz@gmail.com (ORCID: 0000-0001-8962-4343)

IV Engenheiro Florestal, Dr., Professor titular do Departamento de Ciências Florestais, Universidade Federal de Lavras, Aquenta Sol, CEP 37200-000, Lavras (MG), Brasil. trugilho@dcf.ufla.br (ORCID: 0000-0002-6230-5462)

Engenheiro Florestal, Dr., Professor adjunto do Colegiado de Ciências Florestais, Universidade Federal Rural da Amazônia, Rd. PA 257, Km 13, Zona Rural, CEP 68515-000, Parauapebas (PA), Brasil. depaulaprotasio@gmail.com (ORCID: 0000-0002-5560-8350)

vi Físico, Dr., Professor adjunto do Colegiado de Engenharia Química, Universidade do Estado do Amapá, Av. Pres. Vargas, 650, Central, CEP 68900070, Macapá (AP), Brasil. uaitiago@gmail.com (ORCID: 0000-0002-4568-7884)

vII Engenheira Florestal, Dra., Professora adjunta do Instituto de Ciências Agrárias, Universidade Federal Rural da Amazônia, Av. Perimetral, 2501, Terra Firme, CEP 66077-830, Belém (PA), Brasil. linabufalino@yahoo.com.br (ORCID: 0000-0002-7688-3140) 


\begin{abstract}
Despite its social, cultural and economic importance for the Amazon region, the energy potential of Mauritia flexuosa, popularly known as buriti, has not yet been explored in order to expand the possible uses of this species by the local communities. Therefore, the aim of this work was to compare the tissues that comprise the petiole of Mauritia flexuosa for combustion and carbonization. The petiole core and bark were separated and characterized by chemical composition (total and water-soluble extractives, lignin, and ashes), moisture content (based humid mass), proximate composition (contents of volatile matter, fixed carbon, and ash), basic density, higher heating value, and thermogravimetric analysis in $\mathrm{N}_{2}$ inert atmosphere. The two tissues from the Mauritia flexuosa petiole presented advantages for bioenergetic purposes, such as low ash content $(\leq 2 \%)$ and higher heating value $\left(\approx 18 \mathrm{MJ} \mathrm{kg}^{-1}\right)$, in addition to suitable fixed carbon $(\approx 18 \%)$. For the core and husk, the lignin contents ( 19 and $28 \%$, respectively), extractives contents (9 and 5\%, respectively), and basic density (0.041 and $0.267 \mathrm{~g} \mathrm{~cm}^{-3}$, respectively) significantly differed. However, the proximate composition of the tissues was not influenced by such differences, unlike the higher heating value and energy density. The thermogravimetric behavior showed higher degradation ratio and lower final mass yield $(7 \%)$ for the core in comparison to the husk. The husk showed better quality for combustion and carbonization in comparison to the core. This is an advantageous result for the extractive activities of Amazonian communities because the husk is a waste from the petiole processing in order to obtain the core for handcraft. Due to the low basic density, the core can be noted for its use in torrefaction, densification, pyrolysis for the production of bio-oil and production of natural filters and activated charcoals, rather than direct combustion and carbonization.
\end{abstract}

Keywords: Heating value; Energy density; Thermal degradation

\title{
Introdução
}

A biomassa apresenta características favoráveis para produção de energia quando comparada aos combustíveis fósseis, especialmente no que se refere à poluição, em função de seu baixo teor de enxofre $(\mathrm{S})$ e da emissão de dióxido de carbono $\left(\mathrm{CO}_{2}\right)$ na atmosfera geralmente equilibrada pela sua absorção por meio da fotossíntese no desenvolvimento de nova biomassa (KAMBLE et al., 2019). Entretanto, para viabilizar a destinação correta da biomassa para energia, é necessário caracterizá-la, o que consiste principalmente na determinação da sua umidade, densidade, composição química molecular e composição química imediata (PROTÁSIO et al., 2013a). Essas características são amplamente variáveis entre diferentes biomassas madeireiras e não madeireiras (PROTÁSIO et al., 2013b). Adicionalmente, uma mesma biomassa pode possuir componentes ou tecidos com propriedades físicas, químicas e anatômicas diferentes, que podem resultar em carvões heterogêneos no processo de carbonização ou limitar a eficiência de geração de energia na combustão. A possibilidade de melhorar a combustão e a carbonização do resíduo do açaí separando as sementes das fibras lignocelulósicas foi confirmada por Bufalino et al. (2018), em função dos diferentes comportamentos térmicos e teores de minerais desses componentes.

A família das palmeiras Arecaceae é representada por aproximadamente 240 gêneros, que compreendem 2.700 espécies, sendo 250 encontradas no Brasil (LORENZI et al., 2010). Na Amazônia, as palmeiras formam um dos grupos de plantas de grande importância social, cultural e econômica para os habitantes locais, com destaque para a espécie Mauritia flexuosa L. f., vulgarmente conhecida como buriti ou miriti. Trata-se de uma espécie com vários atributos que favorecem sua exploração sustentável, como hiperdominância na região Amazônica (STEEGE et al., 2013), rápida regeneração (SAMPAIO; SCHMIDT; FIGUEIREDO, 2008) e ampla distribuição em habitats úmidos com populações de milhares de indivíduos formando pântanos de palmeiras, conhecidos como buritizais (SANDER et al., 2018). Na Amazônia equatoriana, foi verificado que a extração de até $22,5 \%$ dos indivíduos a cada vinte anos é sustentável ao longo do tempo (HOLM; MILLER; CROPPER, 2008). Dessa forma, a Mauritia flexuosa é recurso natural que pode colaborar na construção de benefícios sociais se submetido ao manejo responsável (CATTANI; BARUQUE-RAMOS, 2016).

Localmente, é conhecida como a "Árvore da Vida", porque todas as suas partes podem 
ser totalmente utilizadas, sendo a principal fonte de renda para muitas pessoas nas comunidades rurais (CATTANI; BARUQUE-RAMOS, 2016). Destinações incluem o fruto para alimentação, o óleo para sabão e cozimento, as fibras das folhas para artesanato, a casca para a construção de cercas, as folhas maduras para a construção de casas e o pecíolo para brinquedos (SAMPAIO; SCHMIDT; FIGUEIREDO, 2008). Entretanto, também apresenta potencial para uso industrial em larga escala (COMPANHIA NACIONAL DE ABASTECIMENTO, 2019), já que em 2018 aproximadamente 300 toneladas de fibras de Mauritia flexuosa foram extraídas no Estado do Pará, sendo o maior produtor o município de Igarapé-Miri com 235 toneladas (IBGE, 2019). Adicionalmente, a exploração de um recurso florestal não madeireiro como esse se apresenta como uma forma alternativa de uso da terra, que contribui mais para a conservação da biodiversidade em comparação com a exploração madeireira (SAMPAIO; SCHMIDT; FIGUEIREDO, 2008).

$\mathrm{Na}$ literatura, os estudos com Mauritia flexuosa estão relacionados, principalmente, as suas sementes, ecologia e tecnologia do fruto. Quanto às aplicações tecnológicas, a maior parte dos estudos está relacionada à qualidade do óleo e utilização de folhas. Sobre o pecíolo, apenas alguns trabalhos foram encontrados (MELO et al., 2016; SOUSA et al., 2017; VIANA et al., 2018), sendo que nenhum desses trata do potencial energético. Assim, a possibilidade de utilização da biomassa proveniente do pecíolo da Mauritia flexuosa para geração de bioenergia pode contribuir para o desenvolvimento local das comunidades ribeirinhas do cenário amazônico, por meio do uso aliado à conservação da espécie. Dessa forma, é necessário investigar os potenciais tecnológicos do pecíolo de Mauritia flexuosa para ampliar suas aplicações e contribuir para geração de renda na Amazônia. Por isso, este trabalho teve o objetivo de comparar a qualidade do miolo e da casca do pecíolo da espécie Mauritia flexuosa para combustão e carbonização, contribuindo para o conhecimento sobre novas biomassas para geração de bioenergia.

\section{Material e métodos}

\section{Coleta e preparo das amostras}

A coleta foi realizada no município de Abaetetuba, pertencente à Mesorregião do Nordeste Paraense e à Microrregião de Cametá, tendo sido coletado material botânico, como folhas e frutos que foram enviados ao Laboratório de Botânica da Embrapa Amazônia Oriental e identificados pelo método de comparação com amostras já identificadas do herbário IAN e confirmadas por especialista.

Para este trabalho, foram selecionadas aleatoriamente sete indivíduos (palmeiras), que apresentaram boa fitossanidade, dos quais foram obtidas duas folhas de cada para posterior retirada do pecíolo. De cada palmeira, um pecíolo foi destinado às análises químicas imediatas, de poder calorífico e termogravimétrico, enquanto o outro à densidade básica. Os pecíolos foram secos ao ar livre entre novembro de 2017 e janeiro de 2018, em seguida, casca e miolo foram separados manualmente com auxílio de estilete.

\section{Análise química e imediata}

Amostras de casca e miolo de um dos pecíolos de cada palmeira foram moídas separadamente em um moinho de facas com rotação de 1750 RPM, acoplado com peneira de 10 mesh (SL32, Solab). As amostras compostas (de cascas ou miolo de diferentes palmeiras)foram, posteriormente, peneiradas para obtenção da fração retida entre 32 e 60 mesh. Todas as análises foram realizadas em triplicatas.

O teor de extrativos totais (com base na massa total) foi determinado de acordo com a norma ABNT NBR 7989 (2010a). Para a determinação de extrativos solúveis em água fria e água 
quente foi utilizada a norma ABNT NBR 14577 (2010b). Conforme as recomendações da norma ABNT NBR 7989 (2010a), o teor de lignina insolúvel (com base na massa livre de extrativos) foi determinado por meio de hidrólise ácida. O teor de cinzas (base massa total) foi obtido seguindo os procedimentos da norma ABNT NBR 13999 (2017). Foi utilizada a norma ASTM D1762 - 84 (2013) de análise imediata para determinar a umidade base úmida, materiais voláteis, teor de cinzas e carbono fixo.

\section{Poder calorífico superior}

O poder calorífico superior foi determinado nas amostras compostas de cascas e miolos das sete palmeiras, seguindo as recomendações da Norma EN ISO 18125 (2017), em uma bomba calorimétrica (C-200, IKA). O poder calorífico inferior (PCI) dos resíduos foi estimado pela Equação 1.

$$
P C I=P C S-206^{*} H
$$

Em que: $P C I=$ poder calorífico inferior $\left(\mathrm{kJ} \mathrm{kg}^{-1}\right) ; P C S=$ poder calorífico superior $\left(\mathrm{kJ} \mathrm{kg}^{-1}\right) ; H=$ hidrogênio considerado $6 \%$, base massa seca.

\section{Densidade básica e densidade energética}

Um pecíolo de cada indivíduo foi seccionado para obtenção de três amostras de $10 \mathrm{~cm}$ de modo a ser distribuído na ponta (próximo ao limbo foliar), no meio e na base (próximo da bainha), conforme Figura 1.

Figura 1 - Amostragem do pecíolo de Mauritia flexuosa: (A) o corte das amostras para determinação de densidade (amostras “M1”, "M” e "M4”); e (B) destaque para uma das amostras para determinação de densidade

Figure 1 - Sampling of the Mauritia flexuosa petiole: (A) cutting of the samples for density determination (samples "M1", "M", and "M4"); and (B) highlighting one of the samples for density determination

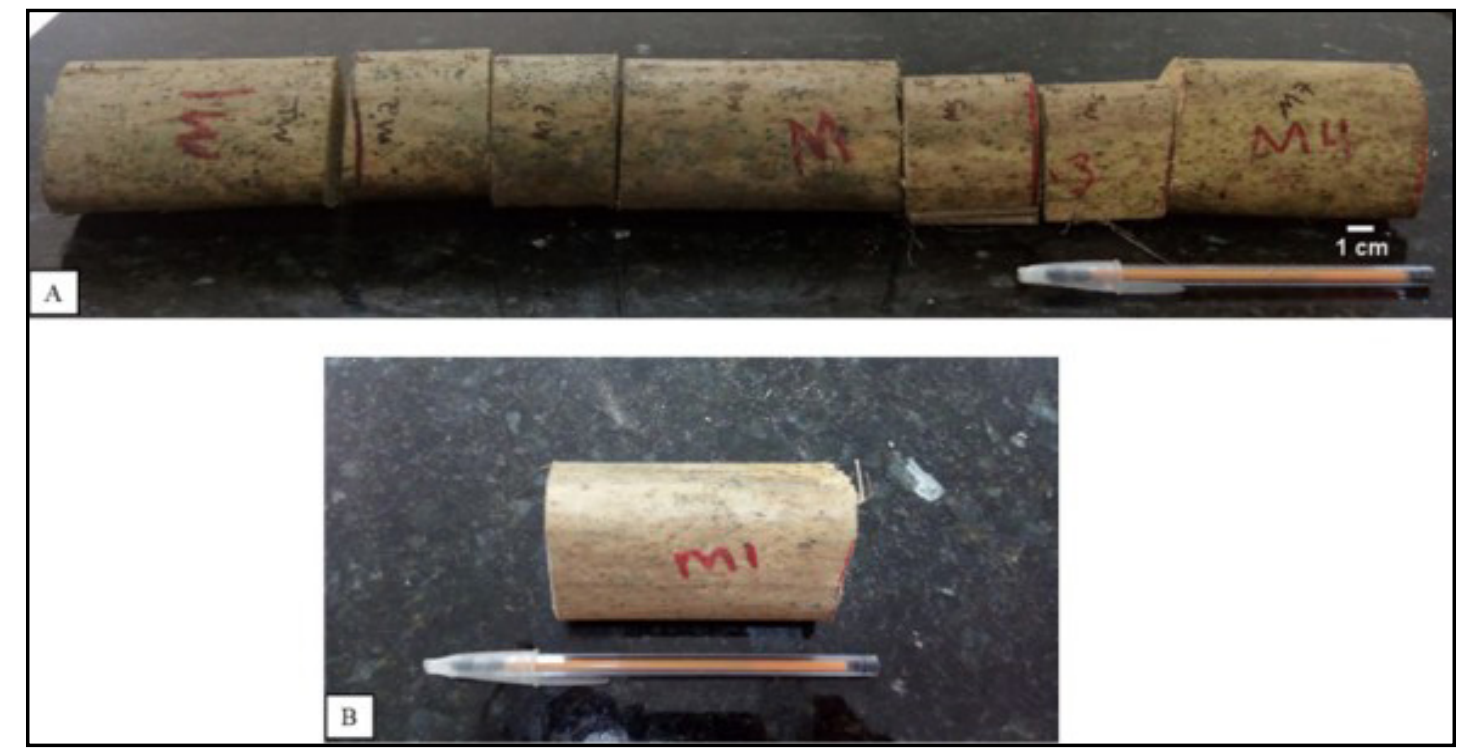

Fonte: Autores (2019) 
Para a determinação da densidade básica $(\mathrm{Db})$ foram adotados procedimentos recomendados pela ABNT MB 1269 (2003). As amostras de casca e miolo foram saturadas em água destilada utilizando uma bomba de vácuo com capacidade de até $30 \mathrm{lbf} / \mathrm{pol}$ e vazão de 35 1/min (Solab, SL-60) até estabilização de volume. Para o procedimento de obtenção do volume foram adicionados aproximadamente $500 \mathrm{~mL}$ de água em um frasco de vidro (béquer), que por sua vez foi posicionado sobre uma balança (precisão de $0,001 \mathrm{~g}$ ) e tarado. Posteriormente, imergiu-se inteiramente a amostra saturada e presa por uma haste na água contida no frasco,com cuidado para que amostra não tocasse nem o fundo nem a lateral do recipiente. Após a imersão, registrou-se o volume deslocado de água, que corresponde ao volume da amostra, considerando a densidade da água igual a $1 \mathrm{~g} \mathrm{~cm}^{-3}$. Após a determinação do volume, as amostras foram secas ao ar livre por $24 \mathrm{~h}$ e, em seguida, armazenadas na estufa a $103 \pm 2^{\circ} \mathrm{C}$ até atingirem a massa absolutamente seca (anidra). A densidade energética (De) foi obtida, conforme Equação 2:

$$
D e=D b^{*} P C S
$$

(Equação 2) $\left(\mathrm{MJ} \mathrm{kg}^{-1}\right)$.

Em que: $D e=$ densidade energética $\left(\mathrm{MJ} \mathrm{m}^{-3}\right) ; D b=$ densidade básica $\left(\mathrm{kg} \mathrm{m}^{-3}\right) ; P C S=$ poder calorífico superior

A densidade média de cada pecíolo foi obtida a partir da média aritmética da densidade das três seções distintas.

\section{Análise termogravimétrica}

Foram utilizados cinco miligramas de amostra seca de cada biomassa (casca e miolo), com granulometria abaixo de 60 mesh, ensaiados no equipamento modelo TGA-60 (Shimadzu). A temperatura do ensaio variou da condição ambiente até $1000^{\circ} \mathrm{C}$ em atmosfera de gás nitrogênio

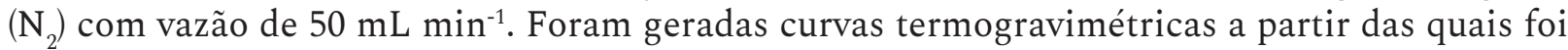
calculada a primeira derivada para identificação dos picos de perda de massa de interesse.

\section{Análise estatística}

As diferenças entre as propriedades da casca e miolo de Mauritia flexuosa foram analisadas por variância univariada (ANAVA) e teste de $\mathrm{F}$ a 5\% de significância, utilizando o software Minitab ${ }^{\circledR} 19$.

\section{Resultados e discussão}

\section{Propriedades químicas, físicas e energéticas dos tecidos do pecíolo de Mauritia flexuosa}

Os teores de extrativos removíveis por água quente e água fria foram significativamente maiores (p-valor $\leq 0,05$ ) no miolo do que na casca (Figura 2). Quando submetido à extração por água fria, o miolo apresentou $8,52 \pm 0,40 \%$ de remoção na massa, enquanto a casca apresentou $4,83 \pm 0,90 \%$. Para teores de extrativos removíveis por água quente, a diferença foi ainda maior, sendo os valores obtidos para miolo e casca 7,84 $\pm 0,36 \%$ e $2,69 \pm 0,47 \%$, respectivamente.

A extração em água fria remove da biomassa os componentes minerais, taninos, gomas, açúcares e materiais coloridos. Em adição, água quente remove amidos (ABNT, 2003). Entretanto, como o tempo de imersão em água fria $(48$ h) prévio à extração é maior em comparação à extração contínua por água quente $(3 \mathrm{~h})$, o primeiro método foi mais eficiente na remoção de extrativos dos tecidos do pecíolo de Mauritia flexuosa. Além disso, extrativos removíveis nas duas condições 
(água fria e água quente), potencialmente, ocorrem em maior quantidade no miolo, porque para o pecíolo esse tecido tem a função de transportar assimilados até a folha, enquanto a casca é a epiderme, tecido de revestimento (GRUSAK; LUCAS, 1984). A quantidade e natureza dos extrativos da biomassa, que não compõe a estrutura da parede celular varia entre biomassas e entre diferentes partes de uma mesma biomassa (PROTÁSIO et al., 2013b; BUFALINO et al., 2018), conforme observado para os dois tecidos do pecíolo de Mauritia flexuosa.

Figura 2 - Comparação entre os teores de extrativos $($ Ext.) removíveis em água fria $(F=$ 400,42; p-valor $\leq 0,05)$ e água quente $(F=106,75 ; p$-valor $\leq 0,05)$ dos tecidos do pecíolo de Mauritia flexuosa $(\mathbf{n}=3)$

Figure 2 - Comparison between the contents of extractives (Ext.) that were removable in cold water $(\mathrm{F}=400.42 ; \mathrm{p}$-value $\leq 0.05)$ and hot water $(\mathrm{F}=106.75 ; \mathrm{p}$-value $\leq 0.05)$ from the Mauritia flexuosa petiole tissues $(\mathrm{n}=3)$

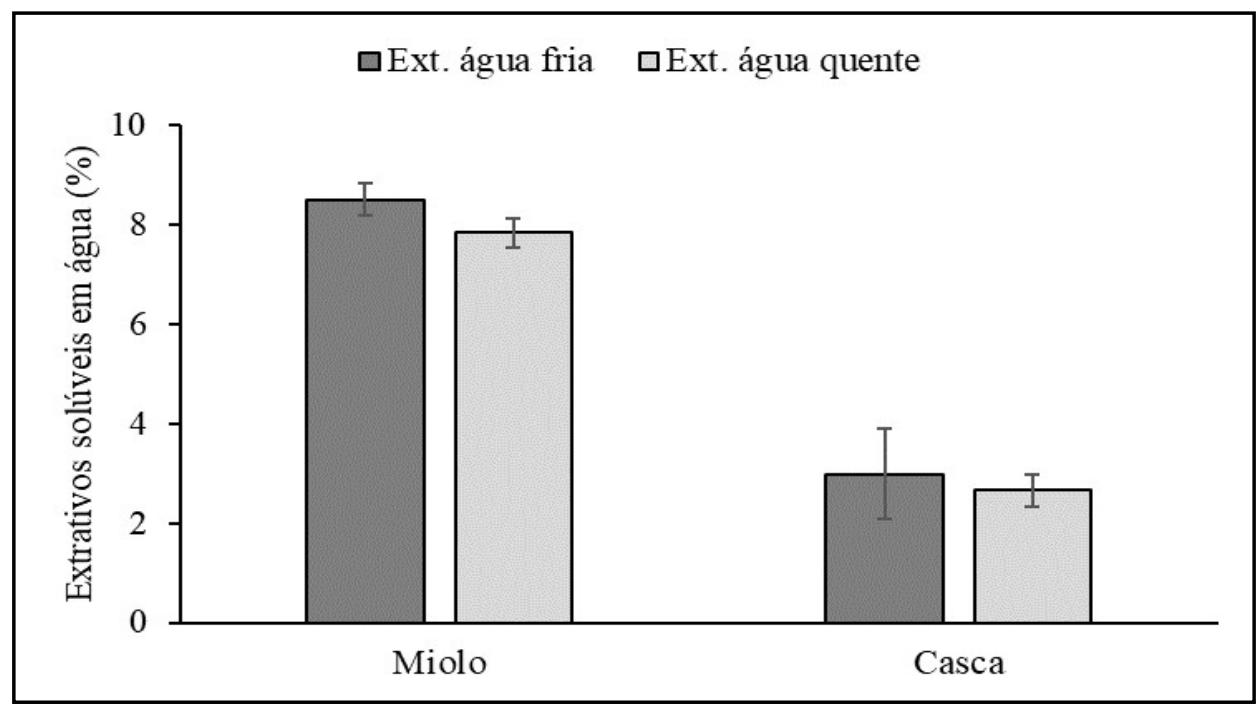

Fonte: Autores (2019)

Geralmente, espera-se que quanto maiores os teores de extrativos totais (extraíveis por solventes polares e apolares), maior seja a energia liberada pela combustão das biomassas (AKDENIZ et al., 2018; DIAS JUNIOR et al., 2019). Entretanto, ressalta-se que as substâncias orgânicas extraíveis em água incluem majoritariamente compostos de baixo poder calorífico (SARTO; SANSIGOLO, 2010) em função da maior relação oxigênio/carbono (O/C) (MAKSIMUK et al., 2020). Adicionalmente, as substâncias inorgânicas extraíveis em água, ou presentes na biomassa, diminuem o poder calorífico (DIAS JUNIOR et al., 2019; SILVA et al., 2020). Assim, a influência positiva ou negativa do maior teor de extrativos removíveis em água encontrado para o miolo no poder calorífico depende da natureza química desses componentes.

Os teores de extrativos totais do miolo $(8,9 \pm 0,15 \%)$ e casca $(5 \pm 0,09 \%)$ diferiram significativamente $(\mathrm{p}$-valor $\leq 0,05)$ e foram um pouco superiores em relação aos teores de extrativos removíveis em água fria, discutidos anteriormente, em função da adicional extração com tolueno e etanol. Na quantificação da lignina, o valor obtido para a casca de $27,83 \% \pm 4,12 \%$ foi significativamente superior ( $\mathrm{p}$-valor $\leq 0,05$ ) ao do miolo de $19,21 \% \pm 2,17 \%$. Já para cinzas, o miolo e casca apresentaram valores estatisticamente iguais de $2,09 \pm 0,07 \%$ e $1,45 \pm 0,04 \%$ (p-valor $\leq 0,05$ ), respectivamente (Figura 3 ).

A diferença nos teores de extrativos totais entre os tecidos foi análoga às observadas para os teores de extrativos removíveis por água fria e água quente, sendo o maior valor encontrado 
ao miolo atribuído à função de transporte de assimilados (GRUSAK; LUCAS, 1984). Esse fato também pode explicar o maior teor médio de minerais encontrados no miolo, já que os nutrientes do solo podem ficar fixados em regiões do tecido antes da realocação em outras partes da planta (NASSER et al., 2016). O menor teor de lignina no miolo em relação à casca pode estar relacionado às grandes quantidades de células de parênquima, enquanto logo abaixo da casca há células de colênquima com parede celular lignificada (NIKLAS, 1999). Goulart et al. (2012) também encontraram diferentes teores de ligninas para diferentes partes da árvore de barbatimão $(22,5 \%$ para o galho, $23,7 \%$ para o fuste e $24,6 \%$ para a raiz).

Figura 3 - Comparação entre os teores de lignina $(F=10,29$; $p$-valor $\leq 0,05)$, extrativos totais $(F=1379,2 ; p$-valor $\leq 0,05)$ e cinzas $(F=170,02 ; p$-valor $\leq 0,05)$ dos tecidos do pecíolo de Mauritia flexuosa $(\mathbf{n}=3)$

Figure 3 - Comparison between the lignin $(\mathrm{F}=10.29 ; \mathrm{p}$-value $\leq 0.05)$, total extractives $(\mathrm{F}=$ 1379.2; $\mathrm{p}$-value $\leq 0.05)$, and ashes $(\mathrm{F}=170.02 ; \mathrm{p}$-value $\leq .05)$ of the Mauritia flexuosa petiole tissues $(\mathrm{n}=3)$

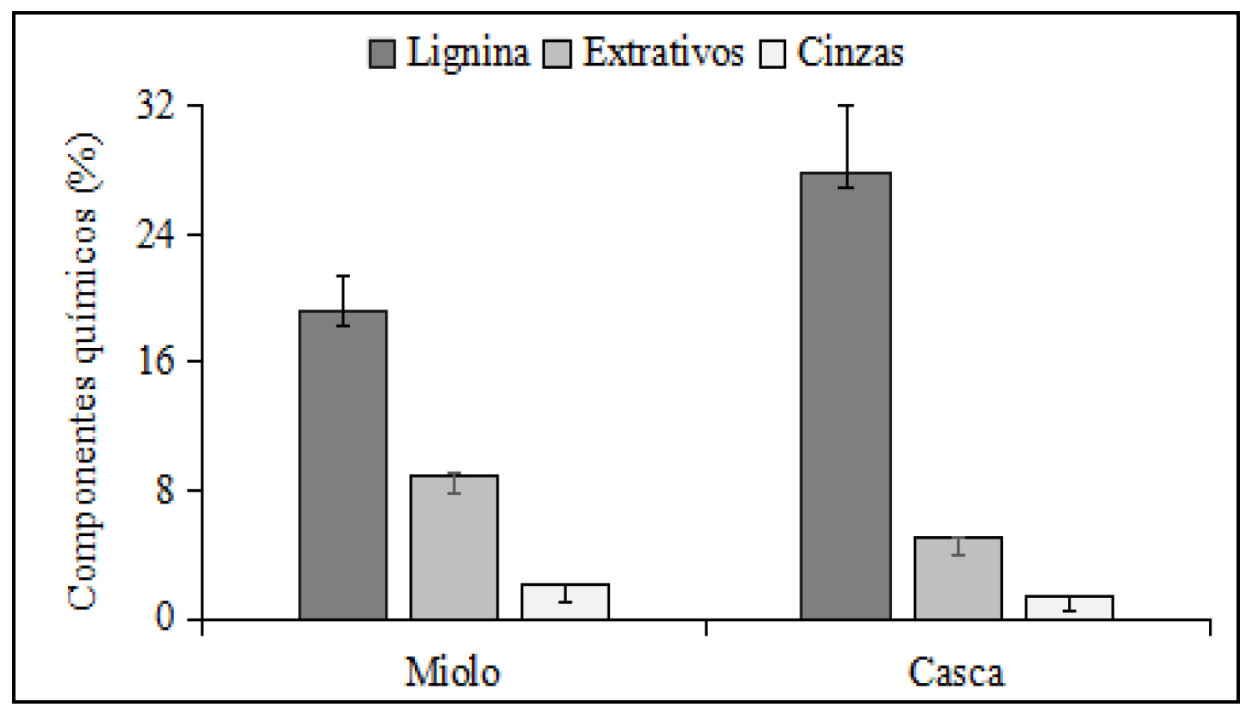

Fonte: Autores (2019)

Conforme discutido anteriormente, o maior teor de extrativos totais da biomassa normalmente afeta positivamente seu poder calorífico (AKDENIZ et al., 2018; DIAS JUNIOR et al., 2019). Entretanto, os teores de extrativos totais, tanto da casca quanto do miolo, foram muito similares aos teores de extrativos removíveis por água fria. Portanto, possivelmente se trata de componentes de baixo poder calorífico em sua maioria. A lignina apresenta maior estabilidade térmica, enquanto a celulose se degrada rapidamente em temperaturas inferiores a $400^{\circ} \mathrm{C}$ em função de quebra das ligações glicosídicas (WANG et al., 2017). Na pirólise, sua decomposição térmica ocorre em ampla faixa de temperatura $\left(100-900^{\circ} \mathrm{C}\right)$ e resulta no maior resíduo sólido (40\% em massa), ou seja, a lignina é a principal responsável por maximizar o rendimento em carvão vegetal (PROTÁSIO et al., 2019). Dessa forma, o maior teor de lignina encontrado para a casca em comparação ao miolo é vantajoso tanto para a carbonização quanto para a pirólise. Já o teor de cinzas corresponde à fração mineral da biomassa que permanece como resíduo após a combustão. Para aplicações energéticas, deve ser preferencialmente baixo, já que os óxidos minerais formam incrustações nos equipamentos e nas tubulações quando queimados em fornalhas, além de reduzirem a facilidade de queima do combustível (PROTÁSIO et al., 2019, PROTÁSIO et al., 2013b). Portanto, com base nessa propriedade, a casca se apresentou com 
melhor qualidade bioenergética em relação ao miolo.

O miolo do pecíolo de Mauritia flexuosa apresentou umidade significativamente inferior ( $\mathrm{p}$-valor $\leq 0,05)$ em relação a sua casca, depois de submetido as mesmas condições de secagem em ambiente. Os teores de carbono fixo, materiais voláteis e cinzas foram significativamente iguais ( $\mathrm{p}$-valor $\geq 0,05$ ) para a casca em comparação com o miolo do pecíolo de Mauritia flexuosa (Tabela 1). Esses resultados indicam que a combustibilidade da casca e do miolo tendem a ser similares, ou seja, o comportamento dessas biomassas durante a combustão não deve diferir significativamente (PROTÁSIO et al., 2019).

Tabela 1 - Comparação entre a umidade e composição imediata dos tecidos do pecíolo de Mauritia flexuosa $(\mathbf{n}=3)$

Table 1 - Comparison between moisture content and proximate composition of the Mauritia flexuosa petiole tissues $(\mathrm{n}=3)$

\begin{tabular}{|c|c|c|c|c|}
\hline \multirow{2}{*}{ Propriedades } & \multicolumn{2}{|c|}{ Tecidos } & \multirow{2}{*}{$\mathbf{F}$} & \multirow{2}{*}{ p-valor } \\
\hline & Miolo & Casca & & \\
\hline Umidade $(\%)^{*}$ & $9,84 \pm 0,79$ & $12,58 \pm 1,05$ & $48,56^{\mathrm{s}}$ & 0,000 \\
\hline $\operatorname{Cinzas}(\%)^{* *}$ & $1,61 \pm 0,54$ & $1,50 \pm 0,46$ & $0,32^{\text {ns }}$ & 0,740 \\
\hline Materiais Voláteis $(\%)^{* *}$ & $80,51 \pm 1,25$ & $79,93 \pm 2,10$ & $0,11^{\mathrm{ns}}$ & 0,576 \\
\hline Carbono fixo $(\%)^{* *}$ & $17,87 \pm 0,89$ & $18,57 \pm 1,74$ & $0,00^{\text {ns }}$ & 0,949 \\
\hline
\end{tabular}

Fonte: Autores (2019)

Em que: Média \pm desvio padrão; *base massa seca; **base massa livre de umidade; S: significativo pelo teste de F a 5\% de significância; e NS: não significativo pelo teste de F a 5\% de significância.

A menor umidade do miolo em comparação à casca pode ser atribuída a sua alta proporção de espaços vazios que resulta na baixa densidade do material. Essa estrutura possibilita que grandes quantidades de água livre (ocupa espaços vazios) sejam absorvidas pelo material, ao invés de água de adesão (liga-se firmemente às moléculas das células), entretanto a água livre também é mais rapidamente perdida durante a secagem natural (LIU et al., 2014). Para combustão de biomassa, o ideal é que a umidade seja inferior $10 \%$, pois umidades muito elevadas (acima de 43\%) não são recomendadas para uso em caldeiras em decorrência do menor poder calorífico. Dessa forma, quanto mais água para evaporar, mais calor é consumido no processo, reduzindo assim seu rendimento energético (GARCÍA et al., 2012). Para essa propriedade, portanto, o miolo se apresentou vantajoso em relação à casca. No entanto, a umidade da casca também ficou pouco acima do limite de $10 \%$ e muito abaixo do teor $43 \%$ acima mencionado.

A composição imediata afeta o poder calorífico e as diversas etapas da combustão. A maior proporção de materiais voláteis em relação ao carbono fixo e cinzas promove maior intensidade da combustão, além de reduzir a temperatura de ignição. Maiores teores de lignina, componente químico estrutural mais estável da biomassa, resultam em maiores teores de carbono fixo e menores teores de materiais voláteis (PROTÁSIO et al., 2019). Entretanto, apesar do maior teor de lignina da casca, casca e miolo apresentaram um teor de carbono fixo similar. Esse resultado pode ser explicado pelo maior teor de extrativos do miolo, sendo alguns desses capazes de serem fixados na fração sólida durante a pirólise (MOULIN et al., 2017). Já as cinzas, resíduos do processo de combustão, diminuem o valor calórico, aumentam a corrosão e os custos com a gestão dos equipamentos de queima (GARCÍA et al., 2013). Na análise imediata, os valores de cinzas foram mais similares entre os tecidos em relação aos observados na Figura 3. Isso ocorre porque os tempos de manutenção na mufla e temperaturas do processo de combustão são 
diferentes nas duas metodologias.

Menor poder calorífico superior e inferior foi constatado para o miolo em comparação com a casca. Adicionalmente, observou-se diferença significativa entre valores de densidade básica da casca e miolo ( $\mathrm{p}$-valor $\leq 0,05$ ), sendo a do miolo muito inferior. Consequentemente, a densidade energética da casca foi aproximadamente sete vezes superior estatisticamente ( $\mathrm{p}$-valor $\leq 0,05)$ à do miolo (Tabela 2).

\section{Tabela 2 - Comparação entre poder calorífico, densidade básica $(n=7)$ e densidade energética $(n=7)$ dos tecidos do pecíolo de Mauritia flexuosa}

Table 2 - Comparison between higher heating value, basic density $(n=7)$, and energy density ( $n$ $=7$ ) of the Mauritia flexuosa petiole tissues

\begin{tabular}{|c|c|c|c|c|}
\hline \multirow{2}{*}{ Propriedades } & \multicolumn{2}{|c|}{ Componente } & \multirow{2}{*}{$\mathbf{F}$} & \multirow{2}{*}{ p-valor } \\
\hline & Miolo & Casca & & \\
\hline Poder Calorífico Superior (MJ kg-1) & 18,31 & 19,00 & - & - \\
\hline Poder Calorífico Inferior (MJ kg-1) & 17,08 & 17,77 & - & - \\
\hline Densidade Básica $\left(\mathrm{g} \mathrm{cm}^{-3}\right)$ & $\begin{array}{c}0,041 \pm \\
0,006\end{array}$ & $\begin{array}{c}0,271 \pm \\
0,066\end{array}$ & $84,29^{\mathrm{s}}$ & 0,00 \\
\hline Densidade Energética $\left(\mathbf{M J ~ m}^{-3}\right)$ & $\begin{array}{c}759,59 \pm \\
113,03\end{array}$ & $\begin{array}{c}5155,28 \pm \\
1252,99\end{array}$ & $85,45^{s}$ & 0,00 \\
\hline
\end{tabular}

Fonte: Autores (2019)

Em que: Média \pm desvio padrão; e S: significativo pelo teste de F a 5\% de significância.

Os resultados de poder calorífico são compatíveis com os maiores teores de lignina e de carbono fixo, encontrados para a casca do pecíolo de Mauritia flexuosa, em comparação com o miolo. Isso ocorre porque a lignina é o componente químico estrutural da parede celular que apresenta maior poder calorífico comparado à celulose e hemiceluloses (KIM; LEE; PARK, 2016; DIAS JUNIOR et al., 2019). O poder calorífico, definido como a medida da quantidade de calor liberado depois da combustão completa da biomassa, é umas das propriedades mais importantes para os projetos energéticos economicamente e ambientalmente viáveis (AKDENIZ et al., 2018).Processos de conversão, como: pirólise, gaseificação e combustão direta dependem muito dessa propriedade (ESTIATI et al., 2016). Portanto, para o pecíolo de Mauritia flexuosa, a casca se apresenta vantajosa em comparação com o miolo.

As densidades básicas encontradas para o miolo $\left(0,0415 \mathrm{~g} \mathrm{~cm}^{-3}\right)$ e casca $\left(0,2670 \mathrm{~g} \mathrm{~cm}^{-3}\right)$ classificam ambos os tecidos como de baixa densidade $\left(<0,550 \mathrm{~g} \mathrm{~cm}^{-3}\right)$, conforme proposto por Silva, Vale e Miguel (2015). A menor densidade resulta em combustão mais rápida da biomassa, o que diminuiu a temperatura máxima e o tempo de manutenção dessa temperatura durante o processo, diminuindo seu rendimento (GAN et al., 2012). Além disso, a densidade da biomassa apresenta relação direta com a densidade do carvão que essa origina. Tal fato torna-a um dos parâmetros mais relevantes para a seleção de espécies na produção de energia a partir de processos termoquímicos (PROTÁSIO et al., 2013b). Portanto, entre os tecidos do pecíolo de Mauritia flexuosa, a casca se apresenta mais vantajosa para a produção de carvão vegetal e combustão direta considerando tanto a sua densidade básica, quanto seu poder calorífico que, consequentemente, resultaram em maior densidade energética. À melhor qualidade técnica da casca em relação ao miolo para as finalidades bioenergéticas se soma o fato de que essa porção é um resíduo gerado da extração do pecíolo de Mauritia flexuosa da floresta, enquanto o miolo é frequentemente destinado à produção de artesanato. Adicionalmente, apesar da baixa densidade intrínseca dos tecidos do pecíolo de Mauritia flexuosa, é 
possível, por exemplo, adaptar sistemas de gaseificação para aproveitamento de biomassas desse tipo que são frequentemente subutilizadas, conforme já demonstrado para a casca de arroz (INDRAWAN et al., 2017). Outra solução seria sua densificação mecânica por peletização ou briquetagem para tornar seu manuseio, transporte e processos de conversão em energia mais eficientes (ORISALEYE et al., 2018). A pirólise pode ainda ser utilizada para converter biomassa de baixa densidade em um produto intermediário de alta densidade (bio-óleo), que pode ser, posteriormente, processado em combustíveis de transporte, como diesel e gasolina (SHARMA et al., 2015). Além disso, uma biomassa naturalmente porosa como é o caso do miolo de Mauritia flexuosa pode ser especialmente atraente para a produção de filtros naturais de carvão ativado (TANG et al., 2017).

O potencial dos tecidos do pecíolo para finalidades bioenergéticas pode ser comparado com outras biomassas madeireiras e não madeireiras (VALE; BRASIL; LEÃO, 2002; NASSER et al., 2016; GHEORGHE; NEACSU, 2019), caracterizadas na literatura (Tabela 3). O miolo e casca do pecíolo de Mauritia flexuosa apresentaram menos extrativos do que a base e raque da folha da palmeira Phoenyx dactylifera. Entretanto, o teor de lignina da casca e miolo de Mauritia flexuosa foi maior e menor em relação àqueles dos componentes de Phoenyx dactylifera, respectivamente. Apesar disso, a relação teor de carbono fixo/materiais voláteis foi maior para os dois tecidos do pecíolo de Mauritia flexuosa. Possivelmente, isso ocorre devido ao teor de cinzas consideravelmente maior na palmeira de Phoenyx dactylifera em comparação com os tecidos do pecíolo de Mauritia flexuosa, o que constitui outra vantagem comparativa dessa espécie. Em comparação com outras plantas não madeireiras, como ervas, os componentes de Mauritia flexuosa apresentam menos cinzas e maior poder calorífico. Entretanto, sua menor densidade aparente se constitui como desvantagem. Exceto pelo maior teor de lignina e densidade aparente da casca de Mauritia flexuosa, o bagaço de cana-de-açúcar apresenta propriedades energéticas mais favoráveis à finalidade bioenergética, especialmente, poder calorífico. Em geral, as madeiras são biomassas de maior densidade, menor teor de cinzas $(<1 \%)$ e maior poder calorífico em comparação às biomassas não madeireiras, conforme os exemplos demonstrados, mas podem demandar mais tempo para crescimento em áreas nativas ou de cultivo.

\section{Tabela 3 - Caracterização de outras biomassas madeireiras e não-madeireiras da literatura (valores médios)}

Table 3 - Characterization of other wood and non-wood biomasses from the literature (average values)

\begin{tabular}{|c|c|c|c|c|c|c|c|}
\hline Biomassa & $\begin{array}{c}\text { Extrativos } \\
(\%)\end{array}$ & $\begin{array}{c}\text { Lignina } \\
(\%)\end{array}$ & $\begin{array}{c}\text { MV } \\
(\%)\end{array}$ & $\begin{array}{l}\text { CF } \\
(\%)\end{array}$ & $\begin{array}{l}\mathrm{Cz} \\
(\%) \\
\end{array}$ & $\begin{array}{c}\text { DA } \\
\left(\mathrm{g} \mathrm{cm}^{-3}\right) \\
\end{array}$ & $\begin{array}{c}\text { PCS } \\
\left(\mathbf{M J ~ k g}^{-1}\right) \\
\end{array}$ \\
\hline $\begin{array}{l}\text { Base da folha da palmeira } \\
\text { Phoenix dactylifera }^{1}\end{array}$ & 24,90 & 25,61 & 76,56 & 13,63 & 9,81 & - & - \\
\hline $\begin{array}{l}\text { Raque da folha da palmeira } \\
\text { Phoenix dactylifera }^{1}\end{array}$ & 17,45 & 26,68 & 82,28 & 14,15 & 3,56 & - & - \\
\hline $\begin{array}{l}\text { Erva } \\
\text { Xanthium Spinosum }{ }^{2}\end{array}$ & - & - & - & - & 6,07 & 0,25 & 16,15 \\
\hline $\begin{array}{l}\text { Erva } \\
\text { Arctium lappa }^{2}\end{array}$ & - & - & - & - & 3,48 & 0,42 & 14,94 \\
\hline Bagaço de cana-de -açúcar ${ }^{3}$ & 16,60 & 26,70 & 86,00 & 13,10 & 0,90 & 0,10 & 18,89 \\
\hline Serragem de eucalipto ${ }^{3}$ & 3,10 & 25,70 & 85,70 & 14,00 & 0,30 & 0,22 & 19,14 \\
\hline Madeira de Sclerolobium paniculatum ${ }^{4}$ & - & - & 78,61 & 21,00 & 0,39 & 0,72 & 20,30 \\
\hline
\end{tabular}

Fontes: ${ }^{1}$ Nasser et al. (2016); ${ }^{2}$ Gheorghe e Neacsu (2019); ${ }^{3}$ Protásio et al.(2013b); ${ }^{4}$ Vale, Brasil e Leão (2002)

Em que: MV: materiais voláteis; CF: carbono fixo; Cz: cinzas; DA: densidade aparente; e PCS: poder calorífico. 


\section{Análise termogravimétrica dos tecidos do pecíolo de Mauritia flexuosa}

Ostecidos do pecíolode Mauritiaflexuosa apresentaram comportamento termogravimétrico similar, porém maior resistência à degradação térmica e menor taxa de perda de massa foram observadas para a casca, quando comparada ao miolo, ou seja, com o aumento da temperatura, o percentual de massa perdida pela casca é menor que o do miolo. Por exemplo, a aproximadamente $321^{\circ} \mathrm{C}$, o miolo perdeu $50 \%$ de sua massa, enquanto a casca só atingiu esse mesmo percentual a $333^{\circ} \mathrm{C}$. O miolo perdeu $7 \%$ mais massa na temperatura final de $600^{\circ} \mathrm{C}$ (Figura 4 ).

\section{Figura 4 - Curvas TG dos tecidos do pecíolo de Mauritia flexuosa em atmosfera de $\mathrm{N}_{2}$}

Figure 4 - TG curves of the Mauritia flexuosa petiole tissues in $\mathrm{N}_{2}$ atmosphere

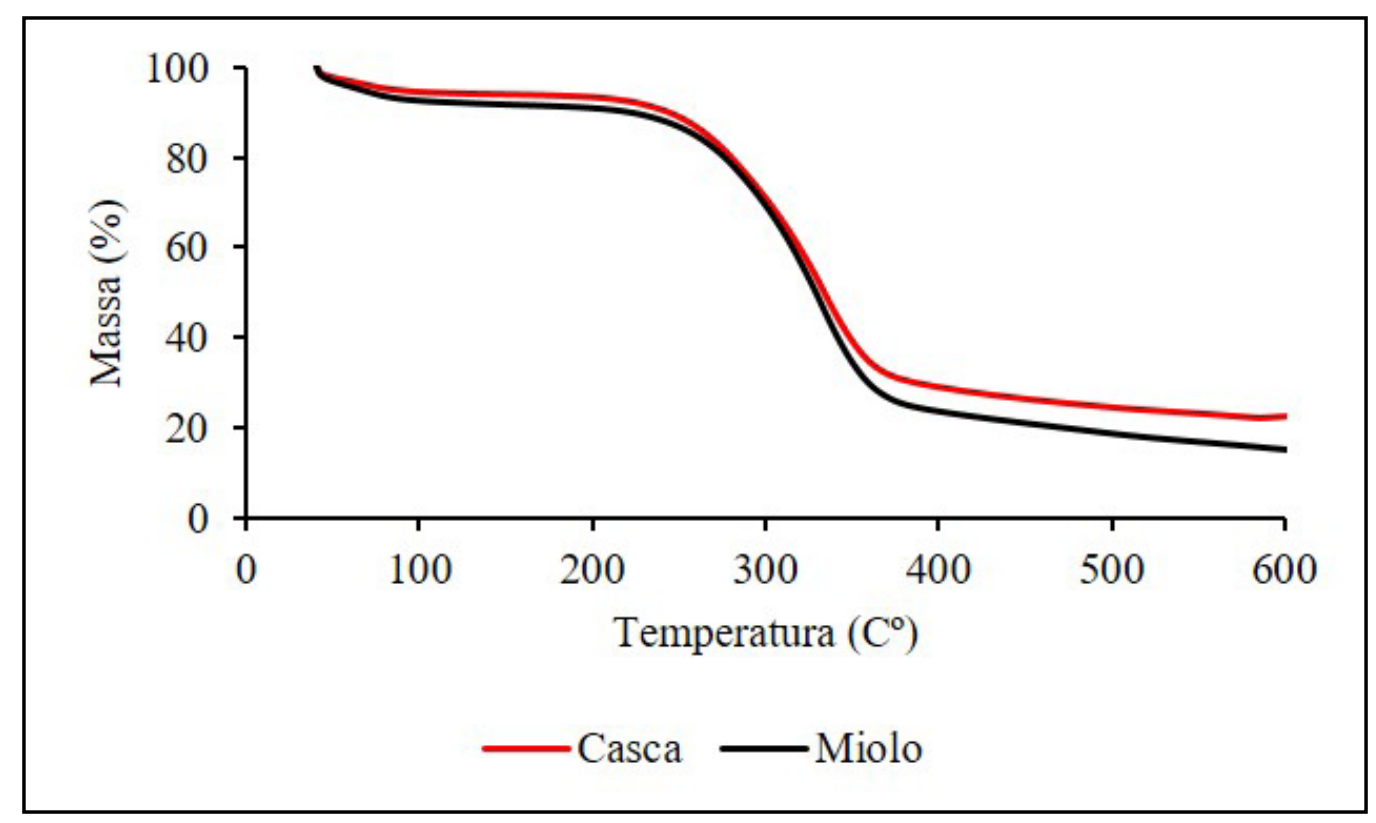

Fonte: Autores (2019)

As diferenças nas taxas de degradação das biomassas estudadas resultam das distintas propriedades químicas e físicas acimas discutidas e evidenciam que, durante a pirólise, casca e miolo do pecíolo de Mauritia flexuosa teriam perdas de massa e rendimentos diferentes (Tabela 4). A degradação mais acelerada do miolo em relação à casca está também relacionada à sua maior área superficial (MOTTIN et al., 2016). A recomendação da separação dos diferentes componentes previamente à produção de carvão foi verificada para o resíduo do açaí (BUFALINO et al., 2018). Além disso, pelas curvas TG é possível gerar informação que sustentam a escolha da temperatura ideal de carbonização (PROTÁSIO et al., 2013a). Ambos os tecidos do pecíolo perderam alto percentual de sua massa após $400^{\circ} \mathrm{C}$, o que significaria um baixo rendimento gravimétrico. Para esses casos, uma alternativa tecnicamente mais viável poderia ser a torrefação da biomassa, que deve ser realizada a temperaturas de aproximadamente até $300^{\circ} \mathrm{C}$ com o objetivo de diminuir a umidade e melhorar a combustão da biomassa (MEI et al., 2015). Observa-se, por exemplo, que na faixa de temperatura típica da torrefação, entre $200-300^{\circ} \mathrm{C}$, o miolo perdeu mais massa comparativamente a biomassa da casca. Esse resultado pode ser atribuído ao teor de lignina da casca de Mauritia flexuosa que ésuperior ao do miolo. 
Tabela 4 - Perda de massa do pecíolo de Mauritia flexuosa de acordo com as faixas de temperaturas

Table 4 - Mass loss of Mauritia flexuosa petiole according to temperature ranges

\begin{tabular}{lcc}
\hline \multirow{2}{*}{ Faixa de temperatura $\left({ }^{\circ} \mathbf{C}\right)$} & \multicolumn{2}{c}{ Perda de massa (\%) } \\
\cline { 2 - 3 } & Casca & Miolo \\
\hline $\mathbf{3 0 - 1 0 0}$ & 5,67 & 7,79 \\
$\mathbf{1 0 0 -} \mathbf{2 0 0}$ & 1,18 & 1,73 \\
$\mathbf{2 0 0 - 3 0 0}$ & 22,57 & 25,51 \\
$\mathbf{3 0 0 - 4 0 0}$ & 41,77 & 42,34 \\
$\mathbf{4 0 0 - 5 0 0}$ & 4,49 & 4,84 \\
$\mathbf{5 0 0 - 6 0 0}$ & 2,00 & 3,39 \\
\hline
\end{tabular}

Fonte: Autores (2019)

As curvas DTG evidenciam nos perfis de decomposição térmica da casca e do miolo do pecíolo, picos de degradação térmica correspondentes aos diferentes componentes químicos da biomassa (Figura 5).

Figura 5 - Curvas DTG dos tecidos do pecíolo de Mauritia flexuosa em atmosfera de $\mathrm{N}_{2}$

Figure 5 -DTG curves of the Mauritia flexuosa petiole tissues in $\mathrm{N}_{2}$ atmosphere

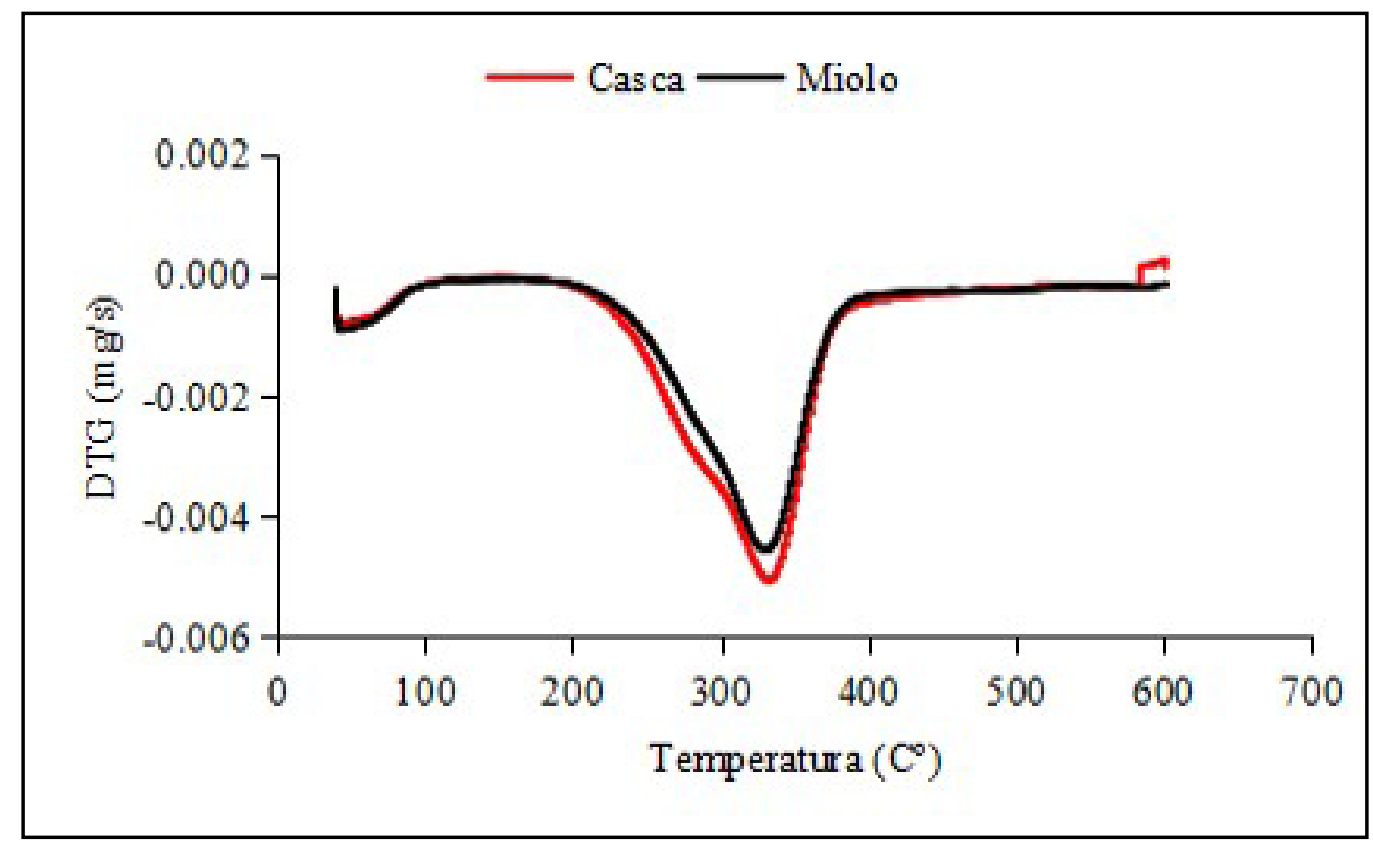

Fonte: Autores (2019)

O primeiro pico ocorre entre a temperatura ambiente de $150^{\circ} \mathrm{C}$, sendo atribuído à evaporação da água da biomassa e os outros dois à degradação de hemiceluloses e celulose, respectivamente (PEREIRA et al., 2013). O pico que aparece entre 180 e $300^{\circ} \mathrm{C}$ é associado à decomposição das hemiceluloses e o segundo, por volta de $360^{\circ} \mathrm{C}\left(300\right.$ e $\left.400^{\circ} \mathrm{C}\right)$, à decomposição da 
$\alpha$-celulose. O pico de lignina é mais largo e aparece entre $200^{\circ} \mathrm{C}$ e $500^{\circ} \mathrm{C}$, com máxima degradação a $350^{\circ} \mathrm{C}$ e aparece sobreposto aos outros dois picos (ALVAREZ; VÁZQUEZ, 2004). A principal diferença entre os tecidos foi o pico das hemiceluloses mais evidente na casca do que no miolo. Os resultados da curva DTG reforçam a melhor estabilidade térmica da casca e a possibilidade de se obter maior rendimento da torrefação e carbonização com essa biomassa, comparativamente ao miolo. Dessa forma, a análise termogravimétrica permite realizar inferências sobre a escolha do processo termoquímico, que poderá ser empregado na conversão dos tecidos de Mauritia flexuosa em combustíveis com melhores propriedades energéticas e com maior rendimento.

\section{Conclusão}

Com a caracterização do pecíolo de Mauritia flexuosa, importante palmeira já explorada na Amazônia para diversas finalidades, visando seu aproveitamento energético, concluiu-se que essa biomassa apresentou vantagens para a produção de energia, como baixo teor de cinzas e teor de carbono fixo e poder calorífico superior, adequados em comparação com outras biomassas vegetais. As propriedades químicas, especialmente teores de lignina e extrativos, e físicas de seus tecidos, miolo e casca, diferiram consideravelmente. Contudo, a composição imediata dessas biomassas não foi influenciada por essas diferenças, ao contrário do poder calorífico e densidade energética. O comportamento termogravimétrico demonstrou taxa de degradação do miolo um pouco superior para o miolo e rendimento final da pirólise superior para a casca. Com exceção da umidade superior, a casca apresentou melhor qualidade para finalidades bioenergéticas, o que do ponto de vista prático pode ser interessante, pois se trata de um resíduo do processamento do pecíolo para obtenção do miolo que já é destinado à produção de artesanatos pelas comunidades locais. As densidades, básica e energética, muito baixas do miolo em comparação com outras biomassas destinadas à combustão e carbonização evidenciam que esse recurso resultaria em baixo rendimento desses processos. Entretanto, esse material tem potencial para outras conversões como torrefação, densificação e pirólise para geração de bio-óleo. A baixa densidade básica do miolo indicou alto potencial para a destinação como filtro natural ou carvão ativado.

\section{Agradecimentos}

O presente trabalho foi realizado com apoio da Coordenação de Aperfeiçoamento de Pessoal de Nível Superior (CAPES) - Código de Financiamento 001, do Conselho Nacional de Desenvolvimento Científico e Tecnológico (CNPq) e da Fundação de Amparo à Pesquisa do Amapá (FAPEAP).

\section{Referências}

AKDENIZ, F. et al. Application of real valued genetic algorithm on prediction of higher heating values of various lignocellulosic materials using lignin and extractive contents. Energy, Oxford, v. 160, p. 1047-1054, 2018.

ALVAREZ, V. A.; VÁZQUEZ, A. Thermal degradation of cellulose derivatives/starch blends and sisal fibre biocomposites. Polymer Degradation and Stability, [s. l.], v. 84, n. 1, p. 13-21, 2004.

AMERICAN SOCIETY FOR TESTING AND MATERIALS. ASTM D1762 - 84: Standard test method for chemical analysis of wood charcoal. West Conshohocken, 2013.

ASSOCIAÇÃO BRASILEIRA DE NORMAS TÉCNICAS. MB 1269: madeira - determinação da 
densidade básica. Rio de Janeiro, 2003.

ASSOCIAÇÃO BRASILEIRA DE NORMAS TÉCNICAS. NBR 7989: pasta celulósica e madeira - determinação de lignina insolúvel em ácido. Rio de Janeiro, 2010a.

ASSOCIAÇÃO BRASILEIRA DE NORMAS TÉCNICAS. NBR 13999: papel, cartão, pastas celulósicas e madeira - determinação do resíduo (cinza) após a incineração a $525^{\circ} \mathrm{C}$. Rio de Janeiro, 2017.

ASSOCIAÇÃO BRASILEIRA DE NORMAS TÉCNICAS. NBR 14577: determinação do material solúvel em etanol-tolueno e em diclorometano e em acetona. Rio de Janeiro, 2010b.

BUFALINO, L. et al. Local variability of yield and physical properties of açaí waste and improvement of its energetic attributes by separation of lignocellulosic fibers and seeds. Journal of Renewable and Sustainable Energy, Oxford, v. 10, n. 5, p. 053102, 2018.

CATTANI, I. M.; BARUQUE-RAMOS, J. Brazilian Buriti Palm Fiber (Mauritia flexuosa Mart.). In: FANGUEIRO, R.; RANA, S. (ed.). Natural Fibres: advances in science and technology towards industrial applications. Dordrecht: [s. n.], 2016. p. 89-98.

COMPANHIA NACIONAL DE ABASTECIMENTO. Boletim da Sociobiodiversidade, Brasília, v. 3, n. 2, p. 1-56, 2019.

DIAS JUNIOR, A. F. et al. Thermal profile of wood species from the Brazilian semi-arid region submitted to pyrolysis. Cerne, Lavras, v. 25, n. 1, p. 44-53, 2019.

ESTIATI, I. et al. Fitting performance of artificial neural networks and empirical correlations to estimate higher heating values of biomass. Fuel, Guildford, v. 180, p. 377-383, 2016.

EUROPEAN COMMITTEE FOR STANDARDIZATION. EN ISO 18125: Solid biofuels determination of calorific value. Genebra, 2017.

GAN, M. et al. Reduction of pollutant emission in iron ore sintering process by applying biomass fuels. ISIJ International, [s. l.], v. 52, n. 9, p. 1574-1578, 2012.

GARCÍA, R. et al. Biomass proximate analysis using thermogravimetry. Bioresource Technology, Essex, v. 139, p. 1-4, 2013.

GARCÍA, R. et al. Characterization of Spanish biomass wastes for energy use. Bioresource Technology, Essex, v. 103, p. 249-258, 2012.

GHEORGHE, D.; NEACSU, A. Heat of some plant biomass species for biofuels production. Revue Roumaine de Chimie, Bucharest, v. 64, n. 7, p. 633-6639, 2019.

GOULART, S. L. et al. Análises químicas e densidade básica da madeira de raiz, fuste e galho de barbatimão (Stryphnodendron adstringens Coville) de bioma cerrado. Cerne, Lavras, v. 18, n. 1, p. 59-66, 2012.

GRUSAK, M. A.; LUCAS, W. J. Recovery of cold-inhibited phloem translocation in sugar beet. Journal of Experimental Botany, Lancaster, v. 35, n. 152, p. 389-402, 1984.

HOLM, J. A.; MILLER, C. J.; CROPPER, W. P. Population dynamics of the dioecious Amazonian palm Mauritia flexuosa: simulation analysis of sustainable harvesting. Biotropica, [s. l.], v. 40, n. 5, p. 550-558, 2008.

INDRAWAN, N. et al. Engine power generation and emission performance of syngas generated from low-density biomass. Energy Conversion and Management, [s. l.], v. 148, p. 593-603, 2017.

IBGE. Produção da extração vegetal e silvicultura 2018. Rio de Janeiro, 2019.

KAMBLE, A. K. et al. Co-gasification of coal and biomass an emerging clean energy technology: status and prospects of development in Indian context. International Journal of Mining Science 
and Technology, [s. l.], v. 29, n. 2, p. 171-186, 2019.

KIM, D.; LEE, K.; PARK, K. Y. Upgrading the characteristics of biochar from cellulose, lignin, and xylan for solid biofuel production from biomass by hydrothermal carbonization. Journal of industrial and Engineering Chemistry, [s. l.], v. 42, p. 95-100, 2016.

LORENZI, H. et al. Flora Brasileira: Arecaceae (Palmeiras). Nova Odessa: Instituto Platorum P.S., 2010. 368 p.

LIU, Y. et al. Novel fluidized bed dryer for biomass drying. Fuel Processing Technology, [s. l.], v. 122, p. 170-175, 2014.

MAKSIMUK, Y. et al. Prediction of higher heating value based on elemental composition for lignin and other fuels. Fuel, Guildford, v. 263, p. 116727, 2020.

MEI, Y. et al. Torrefaction of cedar wood in a pilot scale rotary kiln and the influence of industrial flue gas. Bioresource Technology, Essex, v. 177, p. 355-360, 2015.

MELO, D. de Q. et al. Biosorption of metal ions using a low cost modified adsorbent (Mauritia flexuosa): experimental design and mathematical modeling. Environmental Technology, [s. l.], v. 37, n. 17, p. 2157-2171, 2016.

MOTTIN, A. C. et al. What changes in poly (3-hydroxybutyrate) (PHB) when processed as electrospun nanofibers or thermo-compression molded film? Materials Research, São Carlos, v. 19, n. 1, p. 57-66, 2016.

MOULIN, J. C. et al. Effect of extractives and carbonization temperature on energy characteristics of wood waste in amazon rainforest. Cerne, Lavras, v. 23, n. 2, p. 209-218, 2017.

NASSER, R. A. et al. Chemical analysis of different parts of date palm (Phoenix dactylifera L.) using ultimate, proximate and thermo-gravimetric techniques for energy production. Energies, [s. l.], v. 9, n. 374, p. 1-14, 2016.

NIKLAS, K. J. Research review: A mechanical perspective on foliage leaf form and function. New Phytologist, [s. l.], v. 143, n. 1, p. 19-31, 1999.

ORISALEYE, J. I. et al. Effect of densification variables on density of corn cob briquettes produced using a uniaxial compaction biomass briquetting press. Energy Sources, Part A: Recovery, Utilization, and Environmental Effects, [s. l.], v. 40, n. 24, p. 3019-3028, 2018.

PEREIRA, B. L. C. et al. Estudo da degradação térmica da madeira de Eucalyptus através de termogravimetria e calorimetria. Revista Árvore, Viçosa, MG, v. 37, n. 3, 2013.

PROTÁSIO, T. D. P. et al. Thermal decomposition of torrefied and carbonized briquettes of residues from coffee grain processing. Ciência e Agrotecnologia, Lavras, v. 37, n. 3, p. 221-228, 2013a.

PROTÁSIO, T. P. et al. Assessing proximate composition, extractive concentration, and lignin quality to determine appropriate parameters for selection of superior Eucalyptus firewood. BioEnergy Research, [s. l.], v. 12, p. 626-641, 2019.

PROTÁSIO, T. P. et al. Brazilian lignocellulosic wastes for bioenergy production: characterization and comparison with fossil fuels. BioResources, [s. l.], v. 8, n. 1, p. 1166-1185, 2013b.

SAMPAIO, M. B.; SCHMIDT, I. B.; FIGUEIREDO, I. B. Harvesting effects and population ecology of the buriti palm (Mauritia flexuosa L. f., Arecaceae) in the Jalapão region, Central Brazil. Economic Botany, [s. l.], v. 62, n. 2, p. 172-181, 2008.

SANDER, N. L. et al. Rivers shape population genetic structure in Mauritia flexuosa (Arecaceae). Ecologyand Evolution, [s. l.], v. 8, n. 13, p. 6589-6598, 2018.

SARTO, C.; SANSIGOLO, C. A. Cinética da remoção dos extrativos da madeira de Eucalyptus 
grandis durante polpação Kraft. Acta Scientiarum Technology, Maringá, v. 32, n. 3, p. 227-235, 2010.

SHARMA, A. et al. Process modelling of biomass conversion to biofuels with combined heat and power. Bioresource Technology, Essex, v. 198, p. 309-315, 2015.

SILVA, C. J.; VALE, A. T.; MIGUEL, E. P. Densidade básica da madeira de espécies arbóreas de Cerradão no estado de Tocantins. Pesquisa Florestal Brasileira, [s. l.], v. 35, n. 82, p. 63-75, 2015.

SILVA, S. B. et al. Influence of physical and chemical compositions on the properties and energy use of lignocellulosic biomass pellets in Brazil. Renewable Energy, [s. l.], v. 147, p. 1870-1879, 2020.

SOUSA, S. A. V. de et al. Design and characterization of biocomposites from poly (lactic acid) (PLA) and buriti petiole (Mauritia flexuosa). Journal Renewable Materials, [s. l.], v. 5, n. 3-4, p. 251-257, 2017.

STEEGE, H. et al. Hyperdominance in the Amazonian tree flora. Science, London, v. 342, p. 325336, 2013.

TANG, W. et al.Natural biomass-derived carbons for electrochemical energy storage. Materials Research Bulletin, [s. l.], v. 88, p. 234-241, 2017.

VALE A. T.; BRASIL, M. A. P.; LEÃO, A. L. Quantificação e caracterização energética da madeira e casca de espécies do cerrado. Ciência Florestal, Santa Maria, v. 12, n. 1, p 71-80, 2002.

VIANA, R. V. R. et al. Engaging plant anatomy and local knowledge on the buriti palm (Mauritia flexuosa L. f.: Arecaceae): the microscopic world meets the golden grass artisan's perspective. Cultural Studies of Science Education, [s. l.], v. 13, n. 1, p. 253-265, 2018.

WANG, S. et al. Lignocellulosic biomass pyrolysis mechanism: a state-of-the-art review. Progress in Energy and Combustion Science, [s. l.], v. 62, p. 33-86, 2017. 